Review

\title{
Prenatal and Preimplantation Genetic Diagnosis of Huntington's Disease
}

Joep P.M. Geraedts *

Department of Genetics and Cell Biology, Maastricht University Medical Center, PO Box 1475,6201

BL Maastricht, The Netherlands; E-Mail: joep.geraedts@mumc.nl

* Correspondence: Joep P.M. Geraedts; E-Mail: joep.geraedts@mumc.nl

Academic Editor: Bart Ellenbroek

Special Issue: $\underline{\text { Huntington's Disease Research }}$

OBM Neurobiology

2021, volume 5 , issue 1

doi:10.21926/obm.neurobiol.2101085
Received: December 15, 2020

Accepted: January 18, 2021

Published: January 28, 2021

\begin{abstract}
Huntington's disease (HD) is an autosomal dominant disease that immensely impacts the affected families. However, the transmission of the disease from carriers to their offspring could be prevented. Prenatal diagnosis (PND) and preimplantation genetic diagnosis (PGD) are the only two available reproductive options for the carriers at risk to have disease-free children. PND for HD could be done through two kinds of genetic testing: direct and indirect. The same approaches are available for preimplantation genetic testing. In addition, a third alternative is nondisclosure testing, which is only available in the case of PGD. The pros and cons of different approaches are discussed. However, only a relatively few at-risk parents opt for PND and PGD. Furthermore, compared to PND, PGD is even more seldom opted for as a reproductive option.
\end{abstract}

Keywords: Huntington's disease; reproductive options; genetic testing; prenatal diagnosis; preimplantation genetic diagnosis

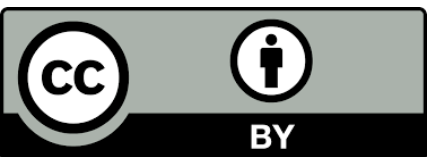

(C) 2021 by the author. This is an open access article distributed under the conditions of the Creative Commons by Attribution License, which permits unrestricted use, distribution, and reproduction in any medium or format, provided the original work is correctly cited. 


\section{Introduction}

Huntington's disease (HD) is a severe progressive neuropsychiatric late-onset disorder, characterized by choreatic movements, psychiatric cognitive deterioration, and affective symptoms [1]. It is a genetic disease with a dominant inheritance pattern and prevalence of 5 to 10 per 100,000 in the Caucasian population. In general, initial symptoms appear between 30 and 50 years, with a mean duration of the disease lying between 17 and 20 years [2].

In 1983, HD was the first genetic disease to be mapped to a chromosomal location using linkage analysis performed using polymorphic DNA markers [3]. Since 1987, linkage analysis of chromosome 4 markers has been used for presymptomatic, predictive, and prenatal testing. However, this requires the presence of positive family history for HD. After the Huntington's Disease Collaborative Research Group found that HD mutation is an abnormal and unstable expansion of a cytosine adenine guanine (CAG) trinucleotide repeat in the Huntingtin (HTT) gene on chromosome 4, it is possible to perform individual genetic testing by directly detecting the mutation, irrespective of the family background [4].

A CAG repeat size of 40 or more is invariably associated with HD. A repeat size of 36 to 39, in the "reduced penetrance" range, could be associated with a later onset in life and sometimes milder clinical symptoms. CAG repeat lengths between 6 and 27 are not believed to be associated with HD. A trinucleotide size between 27 and 35 is considered "intermediate" and does not cause symptoms and signs of HD [5].

At-risk individuals should opt for presymptomatic testing while family planning [6]. However, proven carriers of an HD mutation have a few reproductive options to prevent the transmission of the disease to their offspring. They can either decide not to have children, opt for adoption, or use donor gametes. If they prefer genetically related offspring, they can opt for prenatal diagnosis (PND) or preimplantation genetic diagnosis (PGD) [7]. In this review, I would like to share my more than 25 years' experience in the development of reproductive genetics of HD.

\section{Prenatal Diagnosis}

Prenatal diagnosis of HD was first performed using polymorphic DNA probes linked to the HD locus [8]. Using the amniotic fluid cells or chorionic villus material, the risk of developing HD by the fetus could be predicted with $96 \%$ accuracy [9].

As it was discovered that HD mutation is a CAG expanded repeat, direct testing became available, and the expansion could be tested in the offspring of known HD gene carriers with high reliability [10]. However, for optimal reliability, the DNA of both parents are studied for information with respect to the normal alleles of the HD gene before prenatal testing is offered [11].

Soon after the discovery of the HD locus on chromosome 4, prenatal exclusion testing for offspring at risk was introduced [12]. Exclusion testing avoids the transmission of the HD allele of the affected grandparent without disclosing the disease status of the parent at risk. Thus, a parent with a $50 \%$ risk of having HD could have children with a low risk of HD. The presence or absence of chromosome 4 markers from the affected grandparent to the grandchild by the parent at-risk of $\mathrm{HD}$, is diagnosed using polymorphic markers closely linked to the HD locus. If chromosome 4 markers are inherited from the diseased grandparent, the fetus has a $50 \%$ risk of having HD (the 
same risk as that to the asymptomatic prospective parent). However, this procedure provides no information on the number of CAG repeats of an at-risk individual. After exclusion testing, termination of pregnancy can be offered; however, it is problematic because an average of $50 \%$ of the aborted fetuses will carry a normal grandparental allele and hence will be free of HD [13].

Not only exclusion testing but PND of HD has been ethically problematic for numerous reasons. The first is a selective abortion of fetuses carrying an HD mutation because they might expect about 30 years of disease-free life. Furthermore, if parents decide not to terminate the pregnancy in case of an abnormal test result, this could be problematic for the child, who does not want to know that he/she is carrying the mutation and therefore will develop HD [13].

Several options are available for prenatal diagnosis. At approximately 11 to 12 weeks' gestation, the fetal DNA from the placental material could be obtained by a chorionic villus biopsy. From 16 weeks onward, fetal DNA could be obtained by amniocentesis. Although the latter procedure involves less risk, both procedures are invasive, with a significant risk of miscarriage [14]. Noninvasive testing involves fewer risks for the fetus. In this case, the circulating fetal DNA in the maternal blood could be examined considerably earlier in pregnancy $[15,16]$. However, the use of non-invasive prenatal diagnosis (NIPD) for HD is limited to at-risk pregnancies from an affected father. Furthermore, the strong fragmentation and the short sizes of circulating DNA fragments do not allow the direct detection of these mutations. An alternative approach is to perform analysis on circulating fetal trophoblastic cells (CFTCs) isolated from the maternal blood [17].

\section{Preimplantation Diagnosis}

PGD is the only other alternative for those with an increased risk of HD, who want to have children and do not want to opt for PND [18]. At-risk couples who favor this approach need to undergo medically assisted reproduction. After hormonal stimulation, an average of about ten oocytes is obtained, of which six or seven become fertilized after the medically assisted procedure. Intracytoplasmic sperm injection (ICSI) is preferred over conventional in vitro fertilization (IVF) in monogenic disorders requiring DNA diagnosis to prevent contamination from the sperm still attached to the zona pellucida. After three days, a blastomere of an in vitro developing embryo can be biopsied; however, a biopsy sample is often collected from the trophectoderm as a diagnostic material. Only disease-free embryos are transferred to the uterus to ensure that couples do not face the difficult decision of terminating the pregnancy [19].

The primary disadvantage of PGD is the relatively moderate rate of obtaining a pregnancy [20]. This largely depends on the number of oocytes that can be obtained in the first place and the number of disease-free embryos available for transfer to the uterus after fertilization, biopsy, and diagnosis, because in the case of a dominant disorder such as HD, the potential number of available embryos is reduced by $50 \%$ on average. Other disadvantages are the complexity and the psychological distress of the IVF procedure and the medicalization of reproduction [21].

\section{Comparison between PND and PGD}

Certain patients prefer PGD over PND and selective abortion because the latter approach conflicts with their fundamental beliefs. Moreover, they would like to try PGD after experiencing one or more prenatal diagnoses ending in termination of pregnancy. Finally, they may want to use PGD because they need medically assisted reproduction because of infertility or after sterilization 
[18]. In addition, professionals taking care of patients also differentiate between PND and PGD. In PND, the patients confront the doctors with a pregnancy that has already been established, and the healthcare professionals have to assist them to avoid the birth of a child with the HD mutation. In PGD, the patients require assistance from reproduction specialists to establish the pregnancy. The latter are obliged to take into consideration the interests of the child to be born. In several countries, for example, the UK, the welfare of any child born via assisted conception is of particular importance and is a legal requirement under terms of the Human Fertilization and Embryology Act [22]. This is particularly important if one of the future parents already has signs of the disease [21]. Three different approaches are available for PGD: direct testing, exclusion testing, and nondisclosure testing. PGD through direct CAG-repeat testing was first reported in 1998 [23] and was originally based on the amplification and detection of non-expanded alleles of both partners. The first PGD cycles were only performed for couples who were $100 \%$ informative, implying that the non-expanded allele of the affected parent needed to be different from both alleles of the non-affected parent. Later, as the experience with the assay increased and the expanded allele of the carrier parent was always observed, $50 \%$ of informative couples could be accepted for PGD; this was an important improvement. Both exclusion PGD and nondisclosure PGD are alternatives to direct testing [24, 25]. With both options, the transmission of the HD mutation can be prevented, and the right of at-risk persons not to know his or her genetic status can be respected simultaneously. The principle of PGD exclusion testing is identical to that of prenatal diagnosis. Fetal material is obtained to analyze the transmission of chromosome 4 of both grandparents using markers linked to the HD locus, without revealing the carrier status of the at-risk parent to be. If the HD allele that has been passed to the embryo by the at-risk parent originates from the affected grandparent, the embryo has a $50 \%$ risk of being affected as the transmitting parent. This embryo will be excluded from the transfer. However, only one in two embryos will contain the affected allele. The number of embryos discarded is therefore identical after direct testing and exclusion testing. However, exclusion PGD is ethically more problematic because normal embryos are discarded. In contrast, this is not a unique situation because it is analogous to the use of sex selection of embryos in sex-linked disorders for which no specific test is available, where half of the embryos selected against may not carry the disorder [26].

The third alternative, nondisclosure testing, tests the embryos for HD without informing the prospective parents of the test results. The couples will not receive any information based on which they could conclude whether or any embryos with HD were ever identified [27]. However, in case no embryos are available for transfer, the couple might believe the reason for this could be that all of them were affected. If no affected embryos are present in a large cohort and no pregnancy results are obtained from the treatment, it might not be necessary to offer a second treatment cycle. Therefore, it is difficult to justify assisted reproduction in case an unaffected pregnancy results from natural conception. Furthermore, it will be difficult to conceal all the testing information in a large team of care providers. For these reasons, nondisclosure testing has been challenged [26].

\section{Psychological, Ethical, and Legal Aspects of Testing.}

If a couple with a partner at risk of developing HD is in favor of direct testing, the at-risk patient needs to be tested presymptomatically. In this setting, psychosocial support and counseling should 
be made available before and after the test procedure. Before the test, the patient needs to be appropriately counseled about the implications of undergoing the test and the consequences of different test results that are possible. In addition, the patient requires being aware of the socialeconomic consequences, such as employment and insurance, of a positive test result. Furthermore, an abnormal result could have consequences for family members. Therefore, a predictive testing team not only consists of geneticists but preferably also includes a social worker and specialist who can look after the psychological well-being of the patient. However, the counseling itself can best be done by a geneticist because a survey revealed that neurologists and psychiatrists do not feel comfortable in discussing PGD for HD. The attitudes and practices surveyed among multiple neurologists and psychiatrists revealed that only a minority of these specialists had discussed prenatal diagnosis with their patients and that almost all of them did not feel comfortable discussing PGD [28].

Special attention should be paid at intake to the presence of symptoms indicating the onset of HD. In case minor symptoms are observed, a further discussion on the progression of the disease to evaluate the couple's view on the future is required. If symptoms of HD are observed during intake, a neurologist and a psychologist should be consulted, and the PGD request should be evaluated by the local PGD team and/or occasionally the ethics committee. In general, it is considered that assisted reproduction technology involves shared responsibility for parental caregivers and healthcare providers in respect of a prospective child. If a couple does not appear to be able to provide a stable environment in which the child will grow up, the couple can be rejected for PGD [38].

In the context of predictive testing for $\mathrm{HD}$, an important question is whether it is ethical to provide individuals with information about their future health when no treatment for the condition is available. To assist genetic counselors in dealing with these dilemmas, a set of guidelines for HD predictive testing was developed by the International Huntington Association and the World Federation of Neurology Research Group on Huntington's Chorea [29]. This was updated in 2013 [30]. It is explicitly stated that direct prenatal testing should be performed only if the parent's status is known. If a diagnosis of HD is made on direct prenatal testing of a couple whose carrier status is unknown, there would be enormous implications for the carrier and the partner and other members of the family if the test demonstrates an affected fetus/embryo. If parents with a $50 \%$ risk of HD decide not to be tested themselves, they may prefer to avail themselves of prenatal exclusion testing.

In Europe, the legal aspects and the availability of PGD vary considerably from country to country. PGD and the diseases for which it is allowed are not regulated by law in several European countries. In the United Kingdom, for example, PGD and the conditions for which it has been approved is regulated by a statutory body called the Human Fertilization and Embryology Authority [22]. In certain countries, PGD is prohibited by law, irrespective of the disease, because of the sensitive nature of testing embryos. In countries in which PGD is allowed, it might be prohibited for HD by soft law, mainly because of the late onset of disease. In yet other countries, direct testing (texclusion testing) is allowed. Nondisclosure is more frequently available in the United States because PGD is not regulated at all in that country and may be used for any condition for which genetic testing is available [31]. A division can be seen between countries with and without legislation regulating PGD. Certain countries with legislation have a law permitting PGD (Denmark, Spain, and Sweden). There are only a few countries in Europe forbidding PGD. In 
countries without legislation, for example, Belgium and the Netherlands, PGD is sometimes allowed under the guidance of a national authority. In Norway, PGD is allowed but not for HD [32].

\section{Uptake of PND and PGD}

Since HD frequently occurs in families that are already known to be susceptible and there are a few new mutations, PND and PGD would be used by many individuals to prevent the birth of children with HD. However, there is a large difference between theory and practice [33].

\section{Australia}

Between January 1994 and December 2003, 2,036 direct mutation predictive tests were conducted in Australia, out of which 776 were positive. During this period, 63 prenatal tests were conducted, and 13 children were born with HD following PGD [34].

\section{Canada}

In Canada, predictive testing and prenatal testing for HD are available since 1986. Out of the 425 subjects entering the predictive testing program, 47 subjects or their partners became pregnant. Of this group, only 14 couples requested prenatal testing [35]. In a follow-up study, the uptake, utilization, and outcome of predictive, prenatal, and diagnostic testing in Canada from 1987 to 2000 were reported [36]. A total of 1,061 predictive tests were performed, almost half of which were positive. However, only 15 prenatal tests were requested during this study period.

\section{France}

A study in France reported that out of 354 presymptomatic HD carriers of the mutation, in the age group of 18 to 45 years, only 61 couples requested 101 PNDs. These numbers state that the majority of couples had, on average, almost two prenatal diagnoses. Their final success rate was 75\%. Reproductive decisions differed depending on the outcome of the first PND. If the outcome was favorable, $62 \%$ of couples decided against another pregnancy. However, if unfavorable, $83 \%$ of couples decided for another pregnancy, and the majority (87\%) re-entered the PND procedure [37]. These authors have noted a difference in PND uptake between the population of the Netherlands and more southern populations. This difference is more pronounced if PGD is considered. Although PGD was applied in France in 2001 [24], only a few French centers are conducting PGD, and only one has published a limited number of treatment cycles [38].

\section{The Netherlands}

Numerous studies describe PND and PGD as reproductive options for couples in the Netherlands at risk of transmitting HD to their offspring [38-40]. An overview of prenatal diagnostic testing for HD was presented between 1998 and 2008 and compared with the available data from the previous ten years. The use of PND in the Netherlands remained rather stable since 1996 at about 20 PND tests for HD a year. The estimated uptake of PND was 22\% of CAG expansion carriers at the reproductive age. This figure is higher than in any of the other countries publishing nationwide data [39]. Another study described the reproductive behavior of a cohort of 
couples opting for PND and PGD for HD between 1998 and 2008. It was reported that more females than males underwent genetic testing before procreation. The majority of couples underwent PND; one-third started PGD, whereas a smaller subgroup opted for both. Couples opting for PGD after a previous pregnancy more frequently had a history of pregnancy termination, compared with couples opting for PND after a previous pregnancy. The authors concluded that couples reconsidered their choices in every subsequent pregnancy based on their previous experience, personal beliefs, and the gender of the at-risk partner [40]. Finally, an overview of 13 years of experience of PGD for HD at three European PGD centers in The Netherlands (Maastricht), Belgium (Brussels), and France (Strasbourg) between 1995 and 2008 is provided. About two-thirds of the 331 couples requested direct testing, and one-third requested exclusion testing (with a preponderance of French couples). A history of pregnancy termination after PND was observed more frequently in the direct testing group than in the exclusion group [38].

\section{South Africa}

A total of 287 presymptomatically tested patients in South Africa were reported. Out of these, only $3 \%$ had prenatal testing. The White subjects were overrepresented [41].

\section{United Kingdom}

Certain trends in prenatal and preimplantation testing for HD in the United Kingdom have recently been reported since the start of testing [42].

From 1988 to 2015, 479 prenatal diagnoses were performed for HD. An exclusion approach was used in 150 (31\%) individuals. The annual rate of HD prenatal diagnosis has remained more or less constant despite a steady increase in the use of PGD for HD since 2002. During these 27 years, around 18 prenatal diagnoses were conducted per year.

In a recent study, the UK Huntington's Disease Predictive Testing Consortium recorded 21 pregnancies that were identified as high-risk and then continued. Based on this experience, several considerations for clinical practice have been formulated: (i) reminding couples of the long-term consequences of continuing a high-risk pregnancy, (ii) ensuring that couples understand the information provided, (iii) collaborating closely with other professionals involved in the couple's prenatal care, (iv) preparing the couples for the procedural aspects of prenatal diagnosis and possible termination of pregnancy, ( $v$ ) providing time for in-depth pre-test counseling, (vi) explaining the rationale for only making prenatal diagnosis available subject to conditions, while allowing for human ambivalence and acknowledging that these "conditions" cannot be enforced, (vii) monitoring the whole clinical process to ensure that it works "smoothly," (viii) recommending the couples to not disclose the result of the prenatal test to protect the confidentiality and autonomy of the future "high-risk" child, and (ix) offering on-going contact and support [43].

\section{United States}

To my knowledge, there are no publications on patients with HD in the United States. The center in Fairfax Virginia has published its experience with offering nondisclosure PGD. Ten couples with one partner at a $50 \%$ risk for HD underwent thirteen in vitro fertilization and two 
frozen embryo transfer cycles. Embryos in eleven cycles were free of HD and were transferred and one set of twins and three singleton pregnancies were delivered [44].

\section{Conclusion}

The incidence of HD in European and American populations is higher than that in the remaining world, with an average of approximately 0.5/100,000 [45]. Assuming that the population of Europe and the United States approximates about 1 billion, there will be approximately 40,000 clinically affected individuals with HD. Comparing this number with the numbers given above for different reproductive choices, we conclude an enormous gap between what can presently be done to decrease the incidence of HD and what has been done so far in Europe and the United States. Moreover, approximately fewer than 1 in 1000 births of an infant destined to develop HD is avoided using PND and PGD [33]. Furthermore, the majority of testing considered prenatal diagnosis. In several countries, PGD has not yet been applied or reported.

This implies that several mutation carriers in the reproductive age will not be referred for counseling, do not undergo predictive testing, will refrain from pregnancy, and if they opt for pregnancy, they will not have a PND or preimplantation embryo selection. However, irrespective of the choices made by the couples with an increased risk of transmitting the mutation, it is essential that professionals fully respect their decision and support them [13].

\section{Author Contributions}

Joep Geraedts did all the work.

\section{Competing Interests}

The author has declared that no competing interests exist.

\section{References}

1. Harper PS. Huntington's disease. London: WP Saunders; 1996.

2. Roos RA. Huntington's disease: A clinical review. Orphanet J Rare Dis. 2010; 5: 40.

3. Gusella JF, Wexler NS, Conneally PM, Naylor SL, Anderson MA, Tanzi RE, et al. A polymorphic DNA marker genetically linked to Huntington's disease. Nature. 1983; 306: 234-238.

4. The Huntington's Disease Collaborative Research Group. A novel gene containing a trinucleotide repeat that is expanded and unstable on Huntington's disease chromosomes. Cell. 1993; 72: 971-983.

5. Oosterloo M, Van Belzen MJ, Bijlsma EK, Roos RA. Is there convincing evidence that intermediate repeats in the HTT gene cause Huntington's disease? J Huntingtons Dis. 2015; 4: 141-148.

6. De Die-Smulders CE, de Wert GM, Liebaers I, Tibben A, Evers-Kiebooms G. Reproductive options for prospective parents: Clinical, psychological and ethical reflections. Hum Reprod Update. 2013: 19: 304-315.

7. Geraedts J. Healthy children without fear: Reproductive options for patients or couples carrying inherited diseases. EMBO Rep. 2017; 18: 666-669. 
8. Quarrell OW, Meredith AL, Tyler A, Youngman S, Upadhyaya M, Harper PS. Exclusion testing for Huntington's disease in pregnancy with a closely linked DNA marker. Lancet. 1987; 1: 1281-1283.

9. Hayden MR, Hewitt J, Kastelein JJ, Langlois S, Wilson RD, Fox S, et al. First-trimester prenatal diagnosis for Huntington's disease with DNA probes. Lancet. 1987; 1: 1284-1285.

10. Benjamin CM, Adam S, Wiggins S, Theilmann JL, Copley TT, Bloch M, et al. Proceed with care: Direct predictive testing for Huntington disease. Am J Hum Genet. 1994; 55: 606-617.

11. Tibben A, Dondorp WJ, de Wert GM, de Die-Smulders CE, Losekoot M, Bijlsma EK. Risk assessment for Huntington's disease for (future) offspring requires offering preconceptional CAG analysis to both partners. J Huntingtons Dis. 2019; 8: 71-78.

12. Harper PS, Sarfarazi M. Genetic prediction and family structure in Huntington's chorea. $\mathrm{Br}$ Med J. 1985; 290: 1929-1931.

13. Evers-Kiebooms G, Harper PS, Zoeteweij MW. Prenatal Testing for Late-onset Neurogenetic Diseases . 1st ed. London: CRC Press; 2002.

14. Mujezinovic F, Alfirevic Z. Procedure-related complications of amniocentesis and chorionic villous sampling: A systematic review. Obstet Gynecol. 2007; 110: 687-694.

15. Bustamante-Aragones A, Trujillo-Tiebas MJ, Gallego-Merlo J, Rodriguez de Alba M, GonzalezGonzalez C, Cantalapiedra D, et al. Prenatal diagnosis of Huntington disease in maternal plasma: Direct and indirect study. Eur J Neurol. 2008; 15: 1338-1344.

16. González-González MC, Garcia-Hoyos M, Trujillo-Tiebas MJ, Bustamante Aragonés A, Rodriguez de Alba $M$, Diego Alvarez $D$, et al. Improvement in strategies for the non-invasive prenatal diagnosis of Huntington disease. J Assist Reprod Genet. 2008; 25: 477-481.

17. Cayrefourcq L, Vincent MC, Pierredon S, Moutou C, Imbert-Bouteille M, Haquet E, et al. Single circulating fetal trophoblastic cells eligible for non invasive prenatal diagnosis: The exception rather than the rule. Sci Rep. 2020; 10: 9861.

18. Geraedts JP, De Wert GM. Preimplantation genetic diagnosis. Clin Genet. 2009; 76: 315-325.

19. Handyside AH, Kontogianni EH, Hardy K, Winston RM. Pregnancies from biopsied human preimplantation embryos sexed by Y-specific DNA amplification. Nature. 1990; 344: 768-770.

20. Harper JC, Wilton L, Traeger-Synodinos J, Goossens V, Moutou C, SenGupta SB, et al. The ESHRE PGD consortium: 10 years of data collection. Hum Reprod Update. 2012; 18: 234-247.

21. De Wert G. Dynamics and ethics of preimplantation genetic diagnostics-an exploration. Hum Genet. 1998; 327-357.

22. Human Fertilisation and Embryology Authority. PGD conditions. Available from: https://www.hfea.gov.uk/pgd-conditions/.

23. Sermon K, Goossens V, Seneca S, Lissens W, de Vos A, Vandervorst M, et al. Preimplantation diagnosis for Huntington's disease (HD): Clinical application and analysis of the HD expansion in affected embryos. Prenat Diagn. 1998; 18: 1427-1436.

24. Moutou C, Gardes N, Viville S. New tools for preimplantation genetic diagnosis of Huntington's disease and their clinical applications. Eur J Hum Genet. 2004; 12: 1007-1014.

25. Stern HJ, Harton GL, Sisson ME, Jones SL, Fallon LA, Thorsell LP, et al. Non-disclosing preimplantation genetic diagnosis for Huntington disease. Prenat Diagn. 2002; 22: 503-507.

26. Braude PR, De Wert GM, Evers-Kiebooms G, Pettigrew RA, Geraedts JP. Non-disclosure preimplantation diagnosis for Huntington's disease: Practical and ethical dilemmas. Prenat Diagn. 1998; 18: 1422-1426. 
27. Schulman JD, Black SH, Handyside A, Nance WE. Preimplantation genetic testing for Huntington disease and certain other dominantly inherited disorders. Clin Genet. 1996; 49: 57-58.

28. Klitzman R, Abbate KJ, Chung WK, Ottman R, Leu CS, Appelbaum PS. Views of preimplantation genetic diagnosis among psychiatrists and neurologists. J Reprod Med. 2014; 59: 385-392.

29. International Huntington Association (IHA) and the World Federation of Neurology (WFN) Research Group on Huntington's Chorea. Guidelines for the molecular genetics predictive test in Huntington's disease. Neurology. 1994; 44: 1533-1536.

30. MacLeod R, Tibben A, Frontali M, Evers-Kiebooms G, Jones A, Martinez-Descales A, et al. Recommendations for the predictive genetic test in Huntington's disease. Clin Genet. 2013; 83: 221-231.

31. Bayefsky M. Who should regulate preimplantation genetic diagnosis in the United States? AMA J Ethics. 2018; 20: E1160-E1167.

32. Duguet AM, Boyer-Beviere B. Preimplantation genetic diagnosis: The situation in france and in other european countries. Eur J Health Law. 2017; 24: 160-174.

33. Schulman JD, Stern HJ. Low utilization of prenatal and pre-implantation genetic diagnosis in Huntington disease - risk discounting in preventive genetics. Clin Genet. 2015; 88: 220-223.

34. Tassicker RJ, Marshall PK, Liebeck TA, Keville MA, Singaram BM, Richards FH. Predictive and pre-natal testing for Huntington disease in Australia: Results and challenges encountered during a 10-year period (1994-2003). Clin Genet. 2006; 70: 480-489.

35. Adam S, Wiggins $S$, Whyte $P$, Bloch $M$, Shokeir $M H$, Soltan $H$, et al. Five year study of prenatal testing for Huntington's disease: Demand, attitudes, and psychological assessment. J Med Genet. 1993; 30: 549-556.

36. Creighton S, Almqvist EW, MacGregor D, Fernandez B, Hogg H, Beis J, et al. Predictive, prenatal and diagnostic genetic testing for Huntington's disease: The experience in Canada from 1987 to 2000. Clin Genet. 2003; 63: 462-475.

37. Bouchghoul H, Clément SF, Vauthier D, Cazeneuve C, Noel S, Dommergues M, et al. Prenatal testing in Huntington disease: After the test, choices recommence. Eur J Hum Genet. 2016; 24: 1535-1540.

38. Van Rij MC, De Rademaeker M, Moutou C, Dreesen JC, De Rycke M, Liebaers I, et al. Preimplantation genetic diagnosis (PGD) for Huntington's disease: The experience of three European centres. Eur J Hum Genet. 2012; 20: 368-375.

39. Van Rij MC, de Koning Gans PA, Aalfs CM, Elting M, Ippel PF, Maat-Kievit JA, et al. Prenatal testing for Huntington's disease in the Netherlands from 1998 to 2008. Clin Genet. 2014; 85: 78-86.

40. Van Rij MC, de Koning Gans PA, van Belzen MJ, Roos RA, Geraedts JP, De Rademaeker M, et al. The uptake and outcome of prenatal and pre-implantation genetic diagnosis for Huntington's disease in the Netherlands (1998-2008). Clin Genet. 2014; 85: 87-95.

41. Sizer EB, Haw T, Wessels TM, Kromberg JG, Krause A. The utilization and outcome of diagnostic, predictive, and prenatal genetic testing for huntington disease in johannesburg, South Africa. Genet Test Mol Biomarkers. 2012; 16: 58-62.

42. Piña-Aguilar RE, Simpson SA, Alshatti A, Clarke A, Craufurd D, Dorkins $H$, et al. 27 years of prenatal diagnosis for Huntington disease in the United Kingdom. Genet Med. 2019; 21: 16391643. 
43. Wadrup F, Holden S, MacLeod R, Miedzybrodzka Z, Németh AH, et al. A case-note review of continued pregnancies found to be at a high risk of Huntington's disease: Considerations for clinical practice. Eur J Hum Genet. 2019; 27: 1215-1224.

44. Stern HJ, Harton GL, Sisson ME, Jones SL, Fallon LA, Thorsell LP, et al. Non-disclosing preimplantation genetic diagnosis for Huntington disease. Prenat Diagn. 2002; 22: 503-507.

45. Pringsheim T, Wiltshire K, Day L, Dykeman J, Steeves T, Jette N. The incidence and prevalence of Huntington's disease: A systematic review and meta-analysis. Mov Disord. 2012; 27: 10831091.

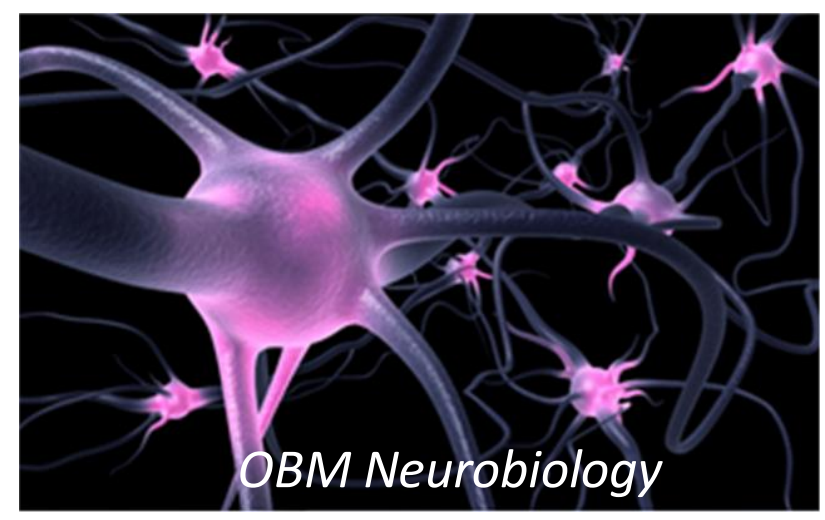

Enjoy OBM Neurobiology by:

1. Submitting a manuscript

2. Joining volunteer reviewer bank

3. Joining Editorial Board

4. Guest editing a special issue

For more details, please visit:

http://www.lidsen.com/journals/neurobiology 